\title{
Characteristics of porous zirconia coated with hydroxyapatite as human bones
}

\author{
V V NARULKAR*, S PRAKASH and K CHANDRA \\ Metallurgical and Materials Engineering Department, Indian Institute of Technology, Roorkee 247 667, India
}

MS received 8 March 2007; revised 7 May 2007

\begin{abstract}
Since hydroxyapatite has excellent biocompatibility and bone bonding ability, porous hydroxyapatite ceramics have been intensively studied. However, porous hydroxyapatite bodies are mechanically weak and brittle, which makes shaping and implantation difficult. One way to solve this problem is to introduce a strong porous network onto which hydroxyapatite coating is applied. In this study, porous zirconia and aluminaadded zirconia ceramics were prepared by ceramic slurry infiltration of expanded polystyrene bead compacts, followed by firing at $1500^{\circ} \mathrm{C}$. Then slurry of hydroxyapatite-borosilicate glass mixed powder was used to coat the porous ceramics, followed by firing at $1200^{\circ} \mathrm{C}$. The porous structures without the coating had high porosities of 51-69\%, high pore interconnectivity, and sufficiently large pore window sizes $(300-500 \mu \mathrm{m})$. The porous ceramics had compressive strengths of 5.3 36.8 MPa, favourably comparable to the mechanical properties of cancellous bones. In addition, porous hydroxyapatite surface was formed on the top of the composite coating, whereas a borosilicate glass layer was found on the interface. Thus, porous zirconia-based ceramics were modified with a bioactive composite coating for biomedical applications.
\end{abstract}

Keywords. Zirconia; porosity; hydroxyapatite; coating; compressive strength.

\section{Introduction}

A lot of research has been carried out to find out a substitute to support bone in the medical field. Presently steel as support for bone are used but due to their corrodability and high density, they need a substitute. Impetus is now on ceramics, since they have high corrosion resistance, better compressive strength and relatively low density hence low weight compared to steel. Porous bioactive ceramics such as hydroxyapatite are attractive for bone regeneration or reconstruction due to their bone bonding ability and good bone in growth property. However, porous hydroxyapatite ceramics are extremely weak. On the other hand, porous zirconia is relatively strong and tough compared to other porous bioceramics, but has the problem of biological inertness to bone tissues. Therefore, it is desirable to combine the mechanical properties of zirconia with the bioactivity of hydroxyapatite. Various studies have indicated the difficulty in obtaining dense zirconiahydroxyapatite composites due to poor sinterability (Silva et al 2001) and decomposition of hydroxyapatite (Kim et al 2005). Thus, it is not feasible to produce useful porous zirconia-hydroxyapatite composite scaffolds. This could be the reason why many studies have turned to hydroxyapatite coatings (or bioactive ceramic coating) on porous

*Author for correspondence (vinaynarulkar@gmail.com) zirconia (or bioinert ceramics) (Silva et al 2001; Nicoli et al 2002; Kim et al 2003, 2004, 2005). When coating porous zirconia with hydroxyapatite, two problems should be considered. Firstly, hydroxyapatite coatings on sintered porous zirconia would result in poor interfacial bonding due to the sintering shrinkage occurring during heating and the thermal shrinkage due to cooling. To improve the interfacial strength of the hydroxyapatite coated porous zirconia, a lesson can be learnt from dense zirconia implants which have been coated with bioactive glass (Nicoli 2002) or glass-ceramic composite (Kim et al 2004). Secondly, plasma spraying technique cannot be used to coat porous ceramics, although it is a good method for dense ceramic.

However, coatings on porous ceramics can be applied by sol-gel coating, ceramic slurry dipping, or biomimetic approach using a simulated body fluid. For example, Kim et al (2003) studied porous zirconia ceramics that were coated with multilayer composite coatings consisting of fluorapatite (FA), hydroxyapatite, and tri-calcium phosphate (TCP) with FA as an intermediate layer. However, there are only a few studies on hydroxyapatite coating on porous zirconia with the coating being modified by a glass phase. Hu and Miao (2004) suggested that borosilicate glass (bioinert and with a low melting point)-hydroxyapatite composite could be used as the coating material for porous zirconia. The purpose of this study was to prepare porous zirconia using an in-house developed method, correlate 
the mechanical properties with the porous structures, and make the porous zirconia ceramics more useful by coating with bioactive hydroxyapatite-borosilicate glass. In this study, borosilicate glass was added into the HA matrix to enhance the interfacial bonding between the coating and the substrate. Borosilicate glass was used because it was readily available, biocompatible, and bioinert.

\section{Experimental}

\subsection{Starting materials}

The starting materials used to prepare the porous bioceramics were $3 \mathrm{~mol} \%$ yttria stabilized zirconia powder (Aldrich Chemical Company, Inc.) with an average particle size of $0.265 \mu \mathrm{m}$ and specific surface area of $4.01 \mathrm{~m}^{2}-\mathrm{g}^{-1}$. Alumina powder (AKP-30) (Sumitomo, Tokyo, Japan) with an average particle size of $0.357 \mu \mathrm{m}$ and a specific surface area of $6.28 \mathrm{~m}^{2} \mathrm{~g}^{-1}$ was also used. Ammonium salt of poly-methacrylic acid (NH4PMAA) solution containing 75 wt. $\%$ water and $25 \%$ active substance, with a molecular weight of 12,000 and a $\mathrm{pH} 8$, was used as a dispersant for ceramic slurries. $\mathrm{HCl}(0 \cdot 1 \mathrm{M})$ and $\mathrm{NaOH}$ $(0 \cdot 1 \mathrm{M})$ were used to adjust $\mathrm{pH}$ of the slurries. Expanded polystyrene (EPS) beads (Styropor ${ }^{\circledR}$ from BASF Singapore Pvt. Ltd.) were used as polymer preform. The average particle sizes of EPS beads were $2.95,2.58,2 \cdot 18,1.85$ and $1.40 \mathrm{~mm}$. The starting materials used for coating were hydroxyapatite (HA) powder (Riedel-de Haëß) with an average particle size of $0.11 \mu \mathrm{m}$ and a Pyrex ${ }^{\circledR}$ borosilicate glass powder with a particle size of $0.50 \mu \mathrm{m}$. The borosilicate glass had the following standard composition: 81 wt. $\%$ of $\mathrm{SiO}_{2}, 4$ wt. $\%$ of $\mathrm{Na}_{2} \mathrm{O}, 0.5$ wt. $\%$ of $\mathrm{K}_{2} \mathrm{O}$, 13 wt. $\%$ of $\mathrm{B}_{2} \mathrm{O}_{3}$, and 2 wt. $\%$ of $\mathrm{Al}_{2} \mathrm{O}_{3}$. The softening point of the glass was $821^{\circ} \mathrm{C}$.

\subsection{Preparation of uniform porous structures}

An in-house designed apparatus for vacuum casting was used to prepare porous structures. The apparatus is schematically shown in figure 1 . The bottom plastic plate with holes was used to support the gypsum plate as a filter. The holes in the plastic plate were to remove water in the ceramic slurry. The EPS beads were packed in a plastic container before casting the slurry. Another plastic plate with holes was used to cover the EPS beads. The plate was then pressed by tightening the two sets of screws and nuts. The pore sizes of the final porous ceramic structures were controlled by using different sizes of EPS beads: $2.95,2.58,2.18,1.85$ and $1.40 \mathrm{~mm}$ and the porosities of the porous structures were controlled by adjusting the screws and nuts.

In the casting process, yttria stabilized zirconia (TZP) or 20 wt. $\% \mathrm{Al}_{2} \mathrm{O}_{3}$ added TZP (ZA20) slurry with a solid loading of 50 wt. $\%$ and a PMAA content of 0.5 and $0.7 \%$, respectively was poured into the plastic container so that the interstices between the beads were filled with ceramic particles. After drying the slurry in air for 2 days, beads were easily removed by turning the set-up upside down and gently tapping on its back. The dried green body was then sintered at $1500^{\circ} \mathrm{C}$ for $2 \mathrm{~h}$. A heating rate of $1^{\circ} \mathrm{C}$ $\min ^{-1}$ was used for heating till $1500^{\circ} \mathrm{C}$.

\subsection{Preparation of HA-glass coating on porous TZP substrate}

HA-50 wt.\% glass mixed powder slurry with solid loading of $25 \mathrm{wt} . \%$ was prepared by planetary ball milling at $100 \mathrm{rpm}$ for $2 \mathrm{~h}$. A dip-coating process was used for the HA-glass coating. Specifically, the porous TZP samples were immersed into the HA glass slurry for $1.5 \mathrm{~min}$. The samples were then centrifuged at $1500 \mathrm{rpm}$ by tying it to a rotary head, to remove the extra slurry. After drying in air, the coated samples were sintered at $1200^{\circ} \mathrm{C}$ in air for $1 \mathrm{~h}$.

\subsection{Characterization}

The morphology of the porous structures was observed by a stereo zoom microscope (Leica MZ6). Scanning electron microscopy (SEM; JEOL, JSM-6310 LV) was used to examine the as-sintered surfaces and the as-polished coating layers on porous TZP substrates. The mechanical properties of the porous structures were studied by an Instron Tester (Model 5567) using a crosshead speed of $0.5 \mathrm{~mm}-\mathrm{min}^{-1}$. The compressive strengths of porous TZP and ZA20 ceramics sintered at $1500^{\circ} \mathrm{C}$ with various pore sizes and porosities were measured using rectangular blocks with dimensions of $10 \times 10 \times 20 \mathrm{~mm}^{3}$. Here hollow block was first filled with powdered material of same density as of TZP and ZA20 and then weighed. Now TZP

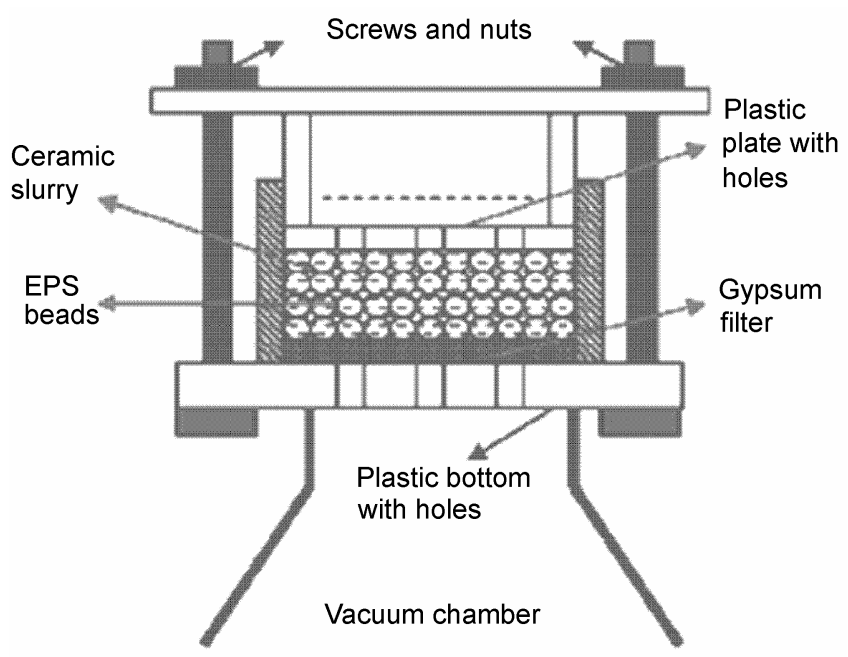

Figure 1. In-house designed apparatus for preparing the porous ceramics. 
and ZA20 were cut of same dimension in rectangular block form of dimension $10 \times 10 \times 20 \mathrm{~mm}^{3}$ and weighed. The differences in weight give porosity of the material. The pore size was measured by the maximum size of sand that pass through the bed.

\section{Results and discussion}

\subsection{Morphology of uniform porous TZP}

3.1a Variation in pore size: The infiltration of a packed EPS bead bed with the TZP slurry resulted in porous TZP after sintering and the porosities of the TZP structures with different pore sizes were about $69 \%$, depending on the applied load on the EPS beads. Porous structures with different pore sizes were obtained using EPS beads of different sizes. Figure 2 shows the porous TZP structures with two different pore sizes. The spherical macropores in the porous TZP ceramics were basically interconnected through pore windows of much smaller sizes, which were typically from $300-500 \mu \mathrm{m}$, estimated from the SEM images. Thus, the obtained porous TZP ceramics had a high porosity and large enough pore window size. Since the porous structures were designed for bone in-growth, thus the pore window (or neck) sizes were important. The oversized pore windows could allow subsequent coating of the bioactive hydroxyapatite layer, which would make the pore window sizes smaller.

However, the bioactive layer coated porous zirconia should have a pore window size of $>100 \mu \mathrm{m}$, as various studies have indicated optimal pore sizes of 100-200 $\mu \mathrm{m}$ for bone in-growth. The proper pore size of a porous bioceramic material should also be determined by considering the mechanical properties such as compressive strength.
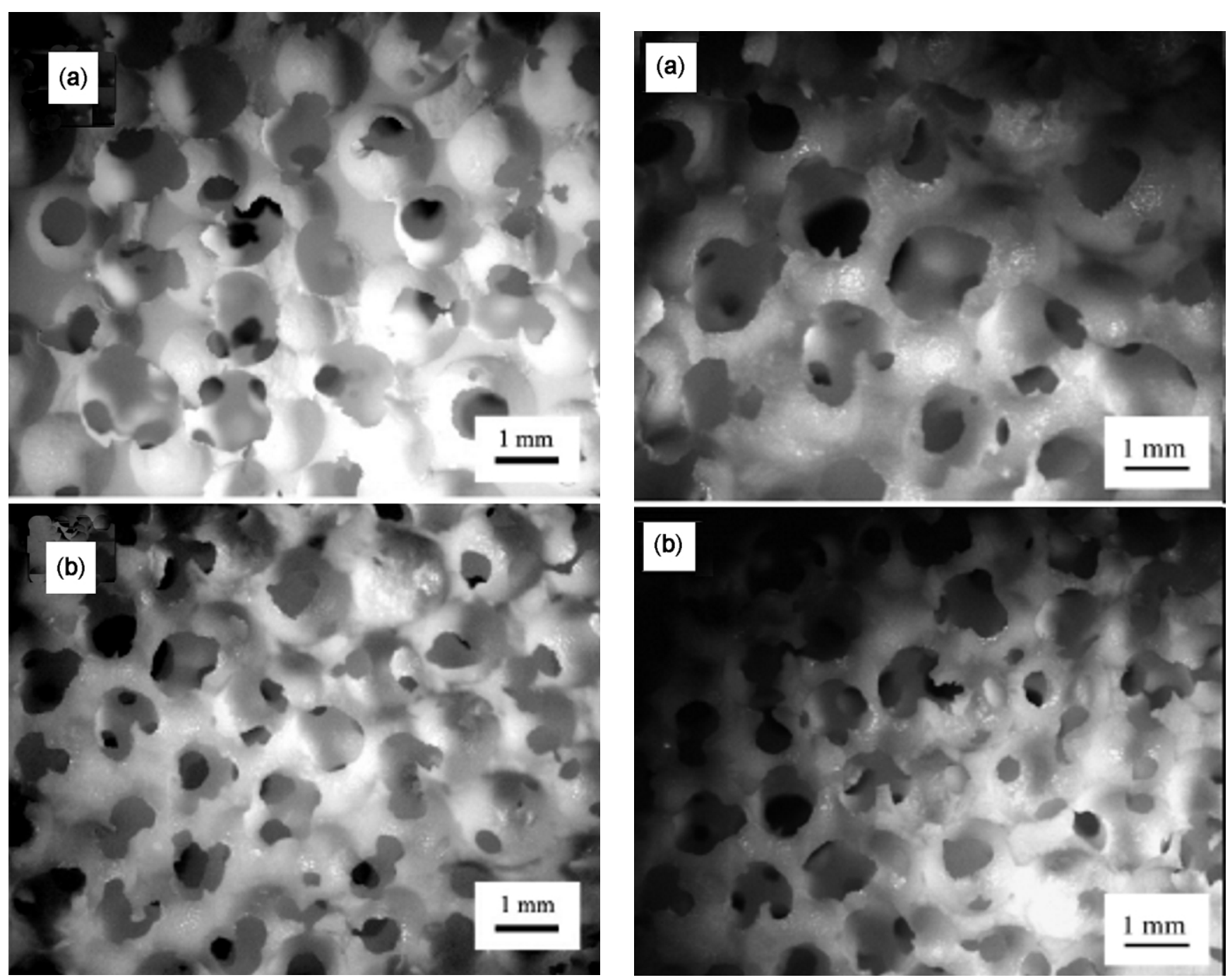

Figure 2. Stereo-optical micrographs showing the porous TZP structures sintered at $1500^{\circ} \mathrm{C}$ that had a porosity of $69 \%$ but different average pore sizes: (a) $1.54 \mathrm{~mm}$ and (b) $0.98 \mathrm{~mm}$

Figure 3. Stereo-optical micrographs showing the porous TZP ceramics sintered at $1500^{\circ} \mathrm{C}$ that had a pore size of $1.29 \mathrm{~mm}$ but different porosities: (a) $62 \%$ and (b) $69 \%$. 
3.1b Variation in porosity: By adjusting the applied load on the bed of the EPS beads, the deformation of the EPS beads or in effect the contacting area between the EPS beads could be controlled and thus uniform porous structures with different porosities and different pore window sizes could be obtained. Figure 3 shows the porous TZP structures with a macro pore size of $1.29 \mathrm{~mm}$ but having two different porosities. From the pictures, one can see that with the increase of porosity, the struts of the porous structure became thinner. Furthermore, the porous structure with a lower porosity had less uniformly distributed pores. However, with the increase of porosity, the macropores became better distributed, the cell edges became more slender and more uniform, and the whole porous structure became more foam-like. The pore window size also increased with the increase of porosity, ranging from $<100 \mu \mathrm{m}$ to about $500 \mu \mathrm{m}$. Thus, too low a porosity was not proper as it resulted in too small a pore window size or pore isolation. On the other hand, if the porosity was too high, the interstices between the contacting EPS beads became too small and thus it became more difficult for ceramic slurry infiltration. Thus the porosity should be also proper and again the final compressive strength of the porous structure should be considered.

\subsection{Compressive strength vs porous structure}

3.2a Effect of pore size on compressive strength: Compressive strength and compressive modulus of the porous ceramics were measured, but only the compressive strength results are presented here.

Figure 4 shows the effect of pore size on the compressive strength of the porous TZP and porous ZA20 structures sintered at $1500^{\circ} \mathrm{C}$ and with a porosity of $51 \%$.

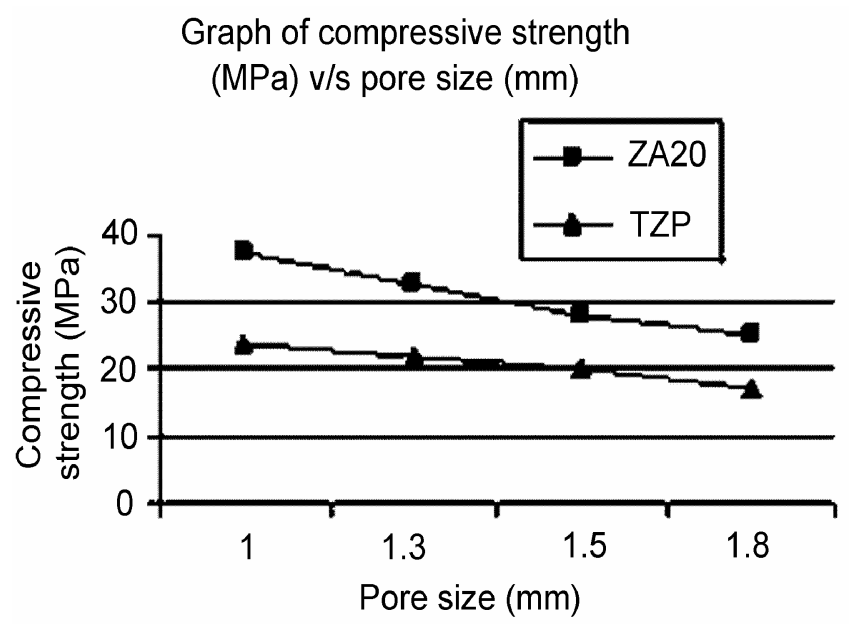

Figure 4. Compressive strength vs pore size for porous TZP and ZA20 structures sintered at $1500^{\circ} \mathrm{C}$ and with a porosity of $51 \%$.
From the figure, one can see that the compressive strength for TZP and ZA20 porous structures decreased with the increase of the pore size. For the porous TZP ceramics, the compressive strength decreased from 23.6$18.9 \mathrm{MPa}$, when the average pore size increased from $0.98-1.85 \mathrm{~mm}$. For the porous ZA20 ceramics, the compressive strength decreased from $36.8-25.8 \mathrm{MPa}$, when the average pore size increased from $1.03-1.8 \mathrm{~mm}$. In spite of the large pore sizes, the present porous ceramics had rather high compressive strengths due to the intrinsically high strength of the materials and also due to the dense ceramic struts as a result of the processing conditions. Although it is not easy to understand why larger pores led to lower strength, this trend was repeatedly observed by us. In addition, Liu (1997) reported a similar compressive strength-pore size relationship in porous hydroxyapatite ceramics. However, Bose et al (2003) showed that the strength of the porous alumina and the porous tricalcium phosphate structures ( $44 \%$ porosity) did not follow a trend of monotonous increase or decrease. In other words, when the pore size was too small $(305 \mu \mathrm{m})$, the compressive strength was decreased. This decreased strength could be due to the incomplete infiltration of the ceramic slurry, resulting in a porous structure with a large number of defects. The decrease of compressive strength due to increasing pore size was also found in porous polymers and porous metals. For example, Ma and Choi (2001) noticed an increase of compressive modulus of porous poly (L-lactic acid) (PLLA) foam $(94.5 \%$ porosity) with the decrease of pore size (from $450-300 \mu \mathrm{m}$ ). On the other hand, for porous magnesium foams ( $45 \%$ porosity), when the pore size varied from $100-400 \mu \mathrm{m}$, the compressive strength changed from 16-10 MPa as shown by Wen et al (2004).

3.2b Effect of porosity on compressive strength: The compressive strengths of the uniform porous TZP and ZA20 ceramics with similar pore sizes $(\sim 1.3 \mathrm{~mm})$ but having different porosities (from 51-69\%) are shown in figure 5. From the figure, one can see that the compressive strength decreased with the increase of porosity. Specifically, for the porous TZP ceramics, the compressive strength varied from $21 \cdot 6-6 \cdot 3 \mathrm{MPa}$, whereas for the porous ZA20 ceramics, the compressive strength varied from 36.8-9.3 MPa. The mechanical properties of these porous TZP and ZA20 ceramics were higher than those of cancellous bones (compressive strength, 2-12 MPa). The dependence of compressive strength on porosity has been established by a few models. For highly porous ceramic structures with interconnected pores, Gibson and Ashby (1997) considered the macro-fracture (crushing) of a porous structure as a result of the bending micro-fracture of the struts and derived the following formula:

$$
\sigma=\sigma_{0}(1-P)^{3 / 2}
$$

where $\sigma$ is the compressive strength of a porous structure at porosity, $P$ and $\sigma_{0}$ the bending strength of the strut mate- 
rial, which may contain micro-pores. It is obvious from (1) that increasing porosity leads to decreasing compressive strength.

\subsection{Effect of alumina addition on zirconia}

In the current study, not only pure porous TZP but also porous TZP-alumina composite were prepared. Studies on dense TZP-alumina composites indicated that alumina could improve the mechanical strength and fracture toughness of pure TZP. As shown in figures 4 and 5 , the compressive strengths of the porous ZA20 ceramics were higher than those of the porous TZP structures. The effect of alumina was mainly because of the thermal expansion coefficient mismatch between the TZP and alumina

\section{Graph of compressive strength} (MPa) v/s porosity (\%)

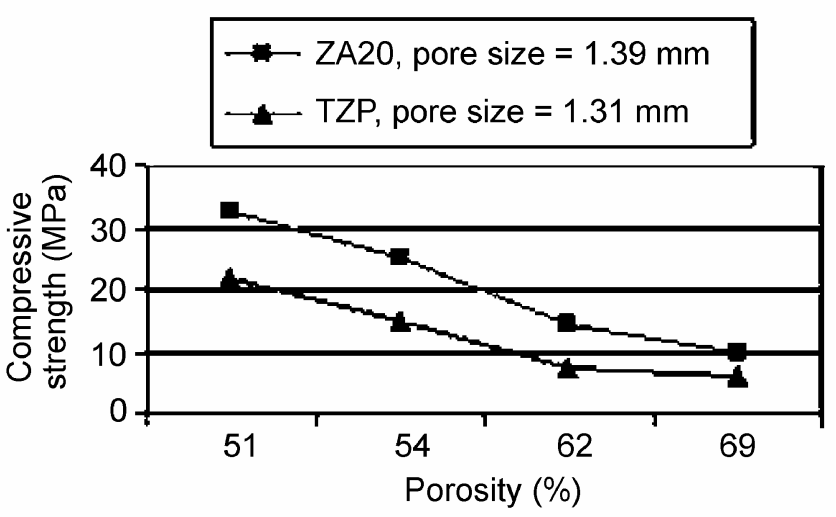

Figure 5. Compressive strength vs porosity for porous TZP and ZA20 ceramics sintered at $1500^{\circ} \mathrm{C}$.

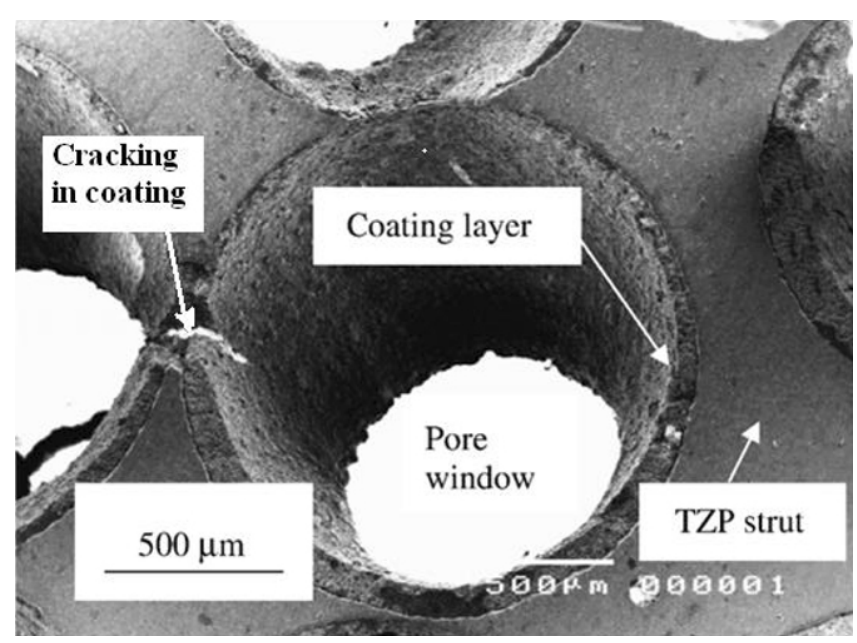

Figure 6. SEM micrograph showing the HA-glass coating on a porous TZP ceramic phases, which caused tensile residual thermal stresses in the composite. The residual stresses tended to reduce the critical stress level required for the tetragonal to monoclinic zirconia phase transformation, which is a well known mechanism of strengthening and toughening in ceramics.

\subsection{Microstructure of HA-glass composite coating}

Figure 6 shows a coated porous TZP ceramic with a pore size of $1.54 \mathrm{~mm}$ and a porosity of $64 \%$. The HA-glass coating layer was about $50 \mu \mathrm{m}$ thick and attached to the pore wall surface of the porous TZP structure. Although the coating layer was relatively thick, the pore windows (up to $500 \mu \mathrm{m}$ ) were not blocked. Figure 7 shows the top surface of the HA-glass coating on the porous structure. The top surface was porous and rich in hydroxyapatite phase. However, the interior part of the coating layer was dense due to the existence of borosilicate glass (softening point, $821^{\circ} \mathrm{C}$ ), which melted at the sintering temperature $\left(1200^{\circ} \mathrm{C}\right)$ and wetted the TZP pore wall surfaces. Thus, the borosilicate glass-rich layer served as an intermediate layer between the bio-inert zirconia and the bioactive hydroxyapatite coating.

Indentation results indicated good interfacial bonding between glass coating and zirconia substrate, as indentation cracking occurred only within the glass layer rather than along the interface as shown in figure 6.

\section{Conclusions}

Porous TZP and ZA20 structures had high porosities of 51-69\%. Most macro-pores were interconnected with pore sizes of 1-2 mm and with pore window sizes of 300$500 \mu \mathrm{m}$. The compressive strength and Young's modulus

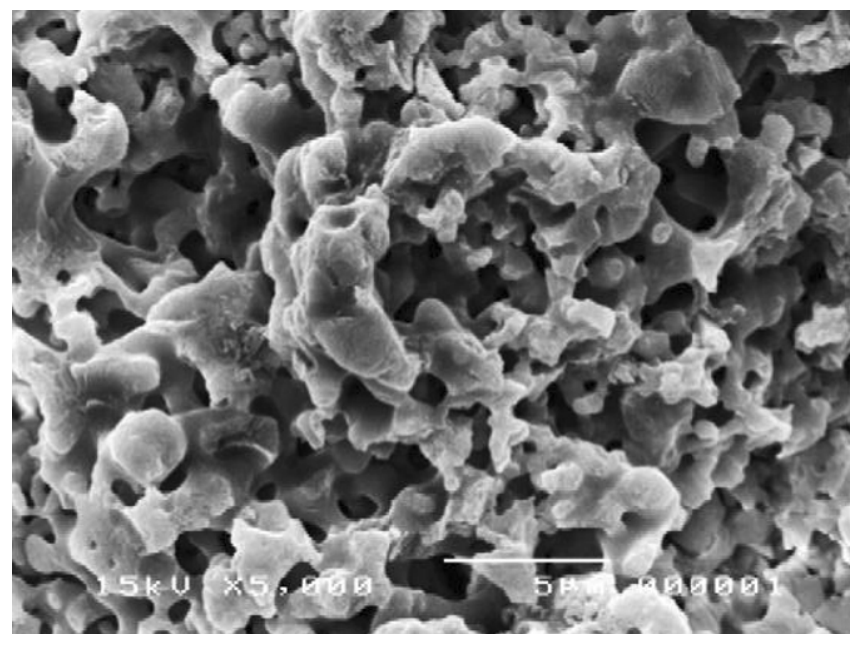

Figure 7. SEM micrograph showing the as-sintered surface of the HA-glass coating layer on the porous TZP structure 
of the porous TZP and ZA20 ceramics all decreased with the increase of pore size and porosity. Depending on pore size and porosity, the porous TZP ceramics showed compressive strengths of 6.3 21.6 MPa and Young's moduli of $0.24 \sim 2.20 \mathrm{GPa}$. On the other hand, the porous ZA20 ceramics had compressive strengths of $9 \cdot 3 \sim 36.8 \mathrm{MPa}$. These data were similar to or better than the mechanical properties of cancellous bones (2 12 MPa for compressive strength). The porous TZP structures were further coated with an HA-borosilicate glass composite layer. The average thickness of the coating layer was $50 \mu \mathrm{m}$. Indentation tests demonstrated good interfacial bonding between the coating layer and TZP substrate. Porous HA surface was formed on the top of the coating and dense borosilicate glass was found in the interior of the coating layer due to the low softening point of borosilicate glass $\left(821^{\circ} \mathrm{C}\right)$ and the high sintering temperature $\left(1200^{\circ} \mathrm{C}\right)$. Thus, porous TZP ceramics with various pore sizes and porosities could be modified by the bioactive composite coating.

\section{References}

Bose S, Darsell J, Kintner M, Hosick H and Bandyopadhyay A 2003 Mater. Sci. \& Eng. B, Solid-State Mater. Adv. Technol. 23479

Gibson L J and Ashby M F 1997 Cellular solids, structure and properties (London: Cambridge University Press)

Hu Y and Miao X 2004 Ceram. Int. 301787

Kim H W, Lee S Y, Bae C J, Noh Y J, Kim H E, Kim H M and Ko J S 2003 Biomaterials 243277

Kim H W, Georgiou F, Knowles J C, Koh Y H and Kim H E 2004 Biomaterials 254203

Kim H W, Knowles J C, Li L H and Kim H E 2005 J. Biomed. Mater. Res. A72 258

Liu D M 1997 Ceram. Int. 23135

Ma P X and Choi J W 2001 Tissue Eng. 723

Nicoli A N 2002 Biomaterials 233833

Silva V V, Lameiras F S and Domingues R Z 2001 Compos. Sci. \& Technol. 61301

Wen C E, Yamada Y, Shimojima K, Chino Y, Hosokawa H and Mabuchi M 2004 Mater. Lett. 58357 